Portland State University

PDXScholar

$11-1-1990$

\title{
A Comparison of Two Vocabulary Tests Used with Normal and Delayed Preschool Children
}

Lynn Safadi

Portland State University

Follow this and additional works at: https://pdxscholar.library.pdx.edu/open_access_etds

Part of the Speech Pathology and Audiology Commons

Let us know how access to this document benefits you.

\section{Recommended Citation}

Safadi, Lynn, "A Comparison of Two Vocabulary Tests Used with Normal and Delayed Preschool Children" (1990). Dissertations and Theses. Paper 4144.

https://doi.org/10.15760/etd.6028

This Thesis is brought to you for free and open access. It has been accepted for inclusion in Dissertations and Theses by an authorized administrator of PDXScholar. Please contact us if we can make this document more accessible: pdxscholar@pdx.edu. 
AN ABSTRACT OF THE THESIS OF Lynn Safadi for the Master of Science in Speech Communication with an emphasis in Speech-Language Pathology presented November $1,1990$.

Title: A Comparison of Two Vocabulary Tests Used With Normal and Delayed Preschool Children.

APPROVED BY THE MEMBERS OF THE THESIS COMMITTEE:

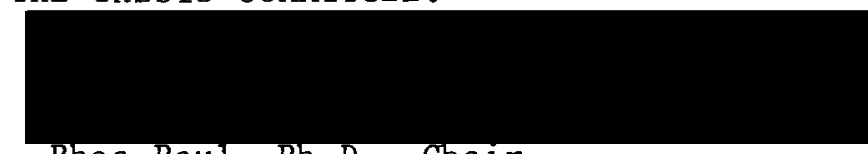

Rhea Paul, Ph.D., Chair

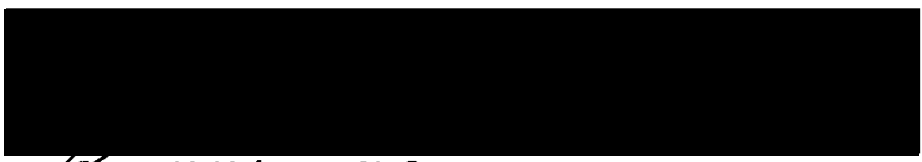

Soan McMahon, M.S.

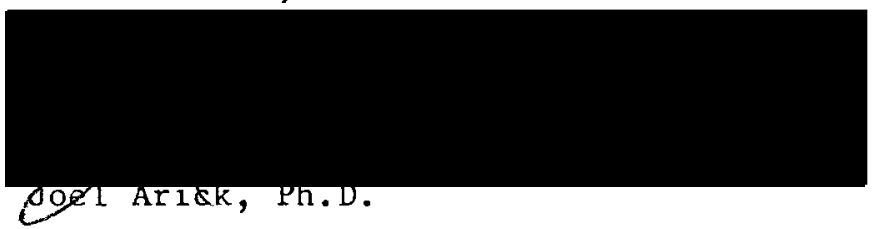

The purpose of this study was to determine if a difference

exists between mean standard scores of the Peabody Picture Vocabulary

Test - Revised (PPVT-R) (Dunn and Dunn, 1981) and the Expressive OneWord Picture Vocabulary Test (EOWPVT) (Gardner, 1979) for children in several diagnostic categories. The subjects used in this study were 45 preschool children ranging in age from 36 to 47 months. These 
subjects were divided into groups of normal, expressively languagedelayed (ELD) and normal children with a history of expressive language delay (HELD).

Results indicated that the only difference in standard score test means was found in the ELD group, exhibiting lower EOWPVT scores. Results also showed a significant moderate correlation between the two tests for total cases. The two tests were also found to moderately correlate with Mean Length of Utterance (MLU), with a stronger association occurring between the EOWPVT and MLU.

The stronger relationship of the EOWPVT to MLU, and the ability of the EOWPVT to correctly discriminate children identified as ELD from normal children support the validity of the EOWPVT as a measure of productive language skill in preschoolers. 
A COMPARISON OF TWO VOCABULARY TESTS USED WITH NORMAL AND DELAYED PRESCHOOL CHILDREN

by

LYNN SAFADI

A thesis submitted in partial fulfillment of the requirement for the degree of

MASTER OF SCIENCE

in

SPEECH COMMUNICATION :

SPEECH AND HEARING SCIENCE

Portland State University

1990 
TO THE OFFICE OF GRADUATE STUDIES:

The members of the Committee approve the thesis of Lynn Safadi presented November 1, 1990 .
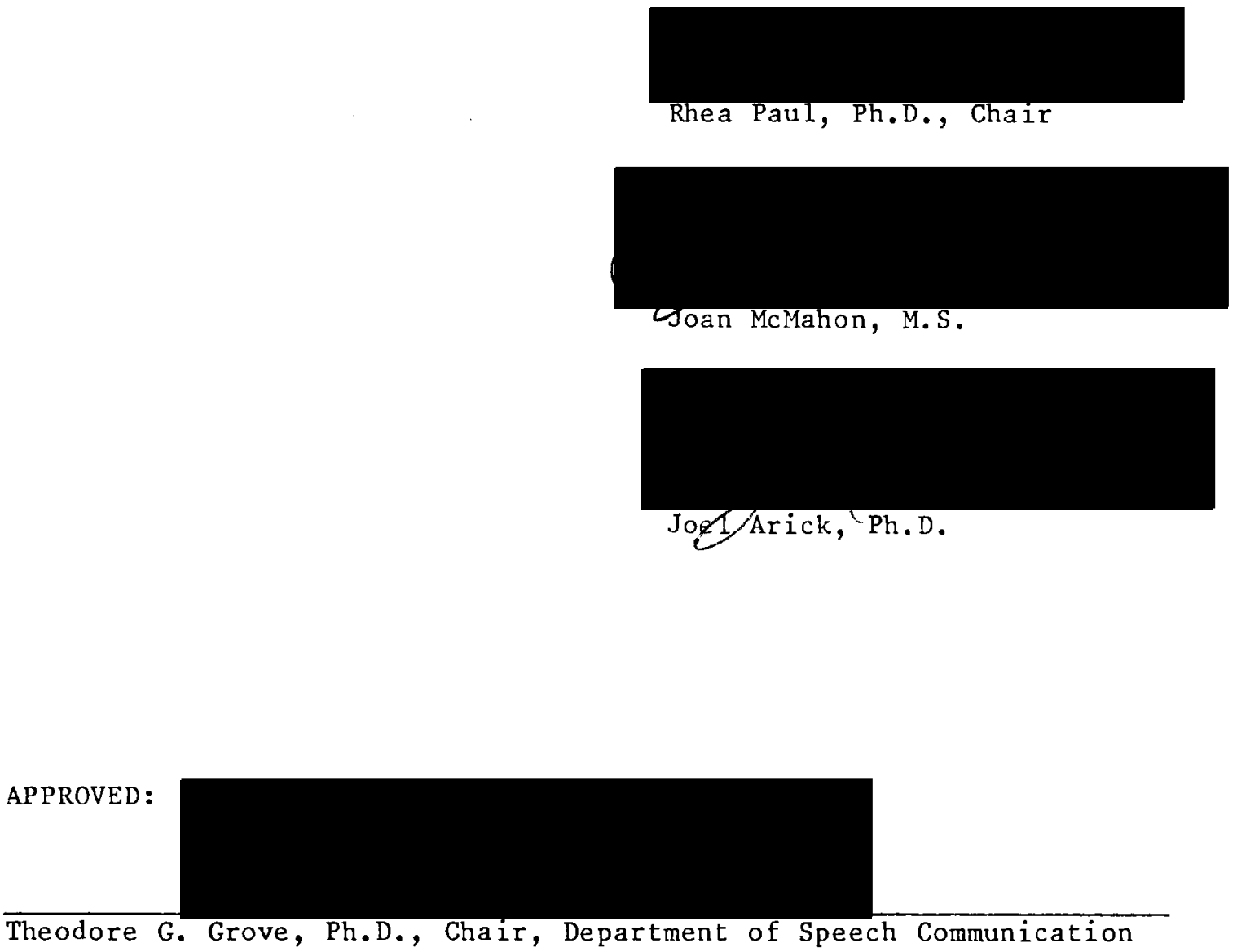

$$
\text { Jof1/Arick,'Ph.D. }
$$

Theodore G. Grove, Ph.D., Chair, Department of Speech Communication

C. William Savery, Interim Vice Provost for Graduate Studies and Research 


\section{ACKNOWLE DGEMENTS}

I am deeply grateful to my parents, Gene and Marion Knutson, for without their continued support and encouragement, my academic achievements would never have been possible.

I offer my sincere gratitude to Rhea Paul, $\mathrm{Ph} . \mathrm{D}$., for her valuable time and assistance in the design and writing of this thesis; and to Joel Arick, Ph.D., for his superior knowledge of statistics.

A special thanks is extended to Joan McMahon, M.S., who has not only been a significant thesis committee member, but has also offered me valuable academic guidance and warm friendship for many years. 
TABLE OF CONTENTS

PAGE

ACKNOWLE DGEMENTS . . . . . . . . . . . . . . . . . iii

LIST OF TABLES . . . . . . . . . . . . . . . . . . . . vi

CHAPTER

I INTRODUCTION . . . . . . . . . . . . . . . 1

Statement of Purpose . . . . . . . . . . . 2

Definition of Terms . . . . . . . . . . . 3

il REVIEW OF THE Literature . . . . . . . . . . . . . 5

Expressive Vocabulary . . . . . . . . . . . 5

Normal Development

Delayed Development

Receptive Vocabulary . . . . . . . . . . 11

Normal Development

Delayed Development

Relationship Between Receptive and Expressive

Development . . . . . . . . . . 14

Normal Development

Delayed Development

Summary of Vocabulary Development . . . . . . 16

Peabody Picture Vocabulary Test - Revised . . . 16

Expressive One-Word Picture Vocabulary Test . . 21

Peabody Picture Vocabulary Test and the Expressive

One-Word Picture Vocabulary Test . . . . . 23

Summary of Tests . . . . . . . . . . . 24 
III METHODS AND PROCEDURES . . . . . . . . . . . . 26

Methods ................. 26

Subjects

Assessment Instrumentation . . . . . . . . 28

Peabody Picture Vocabulary Test (PPVT-R)

Expressive One-Word Picture Vocabulary Test (EOWPVT)

Procedures . . . . . . . . . . . . 29

Intake Evaluate at Age Two

Follow-Up Evaluation at Age Three

Data Analysis

IV RESULTS AND DISCUSSION . . . . . . . . . . . 31

Results . . . . . . . . . . . . . 31

Discussion . . . . . . . . . . . 33

V SUMMARY AND IMPLICATIONS . . . . . . . . . . . 35

Summary •. . . . . . . . . . . . . 35

Implications . . . . . . . . . . 36

Research Implications

Clinical Implications

REFE RENCES

APPENDICES

A DEMOGRAPHIC DATA . . . . . . . . . . . . 43

B PARENTAL CONSENT FORM ............... 47

C LANGUAge DeVelopment SURVEY . . . . . . . . . . . . 49

D PEABODY PICTURE VOCABULARY TEST - REVISED . . . . . . 51

E EXPRESS IVE ONE-WORD PICTURE VOCABULARY TEST . . . . . . 54 


\section{LIST OF TABLES}

TABLE

PAGE

I Age Ranges, Means, and Standard Deviations for

the Norma1, ELD and HELD Groups . . . . . . .

II Socio-Economic Status Ranges, Means and Standard

Deviations and Sex Distributions for

Each Group . . . . . . . . . . . . .

III MUU Ranges, Means, and Standard Deviations for

the Norma1, ELD and HELD Groups . . . . . . . 30

IV Standard Score Ranges, Means, and Standard Deviations

of the PPVT-R and the EOWPVT for Each Group ...

V t-Test Values of the PPVT-R vs. EOWPVT Standard

Score Means for Each Group and Total Cases ...

VI Pearson $r$ Correlations for the PPVT-R, EOWPVT, and

MLU for Total Cases... . . . . . . . . 
CHAPTER I

\section{INTRODUCTION}

It is one of the primary interests of the speech-language pathologist to identify children with language delays and disorders. One area of concern to the clinician is the child's vocabulary. Because expressive and receptive vocabulary may be somewhat different, it is often helpful to assess these areas independently. In order to do so, the clinician utilizes measurement procedures that are confirmed to be reliable and valid for an intended population.

The Peabody Picture Vocabulary Test - Revised (PPVT-R) (Dunn and Dunn, 1981) and the Expressive One-Word Picture Vocabulary Test (EOWPVT) (Gardner, 1979) are two such tests commonly used to measure vocabulary development, receptive and expressive, respectively. In reviewing the literature, however, there appears to be limited data in interpreting the validity of the PPVT-R and EOWPVT scores in normal children (Channe11 and Peek, 1989; Teuber and Furlong, 1985). Thus, it becomes necessary to further examine these two measures in interpreting their scores with delayed children. 
STATEMENT OF PURPOSE

The purpose of this study will be to determine if there is a difference between mean standard scores of the PPVT-R and the EOWPVT in children in several diagnostic categories.

Such a study would provide additional concurrent validity to the EOWPVT in comparison to the well established PPVT-R. Further, if there is disagreement between these two tests, this information will be important for clinical decision making. Knowing the ways in which normal children score on the two tests will aid in the interpretation of scores for delayed children. Also, knowing how delayed children typically score on both tests will help in evaluating the results of the two tests for a particular delayed child.

Hence, the research question this study will attempt to answer is: Is there a significant difference between group mean standard scores of the PPVT-R and the EOWPVT within groups of normal threeyear-olds, children with expressive language delays (ELD) and children with a history of expressive language delay (HELD). This in turn led to the following null hypothesis: There will be no significant difference between group mean standard scores of the PPVT-R and the EOWPVT within groups of normal, ELD and HELD three-year-old children. 
DEFINITION OF TERMS

The following definitions will be utilized throughout this study.

1. Expressive Language Delayed (ELD) Subjects.

A. At age two:

Children 24 to 34 months of age and producing less than fifty words or using no two-word combinations.

B. At age three:

Children 36 to 48 months of age with a Mean Length of Utterance (MLU) 1 standard deviation or more below chronological age (Miller, 1981).

2. Normal Language Subjects.

A. At age two:

Children 24 to 34 months of age and producing more than fifty words and using two-word combinations.

B. At age three:

Children 36 to 48 months of age with an MLU within 1 standard deviation of chronological age (Miller, $1981)$

3. History of Expressive Language Delay (HELD) Subjects. At age two were considered delayed by above expressive vocabulary size and word combination criteria, but at age three were normal in terms of MLU. 
4. Subject's Receptive Vocabulary.

Receptive vocabulary will be determined by standard

scores obtained from the Peabody Picture Vocabulary

Test - Revised.

5. Subject's Expressive Vocabulary.

Expressive vocabulary will be determined by standard scores obtained from the Expressive One-Word Picture Vocabulary Test. 


\section{CHAPTER II}

\section{REVIEW OF THE LITERATURE}

The process of communication involves the ability to encode (express) and decode (comprehend) messages to exchange information and ideas with others. Words are the first linguistic forms acquired, and vocabulary size, both expressive and receptive, increases throughout the life span (Owens, 1988).

A discussion of normal and delayed development of expressive and receptive vocabulary in young children will be presented, as well as the relationship between these two modalities. The Peabody Picture Vocabulary Test - Revised and the Expressive One-Word Picture Vocabulary Test will be reviewed as they represent the two primary instruments used in this study.

\section{EXPRESSIVE VOCABULARY}

\section{Norma 1 Deve lopment}

In the first few months of life, the infant begins the process of language acquisition. The infant is able to respond to language addressed to him/her, as well as participate through gestures and vocalizations. By the end of the first year of life, the infant 
begins to assert more control when interacting with others, and its intentions are communicated more clearly and effectively.

Sometime around the first birthday, the child's first words appear. Although there is much individual variation as to the age first words appear, they generally refer to particular situations, actions and objects. Initially, these may be restrictive in meaning and apply to a particular referent (Bloom, 1974). For example, "doggie" may only refer to the child's pet, but not to other dogs. Most of the child's first words will contain one or two syllables and will be somewhat restricted in syllabic construction (Owens, 1988). First words have also been found to be dependent on the child's phonological capabilities. Young children are more likely to produce words containing sounds already in their repertoires than words with sounds absent from their phonologies (Leonard, Schwartz, Chapman, Rowan, Prelock, Terre11, Weiss, and Messick, 1982 ; Schwartz and Leonard, 1981). Ingram (1976) noted that shortly after acquiring a lexicon of 50 words, children decreased in their tendency to avoid using certain sounds.

The second half of the second year is a period of accelerated vocabulary growth. By 18 months, the child will produce approximately 50 words. It is generally agreed upon that noun or object words predominate (Benedict, 1979; Huttenlocher, 1974; Gentner, 1978). Most nouns refer to specific people, animals, and objects within the child's environment. Among the first 50 words produced, approximately 60 to 65 percent are nouns, 20 percent are action words, while modifiers, personal-social, and functional words make up 
the final 15 to 20 percent of the first 50 words. The single-words are used not only to label, but to make requests, comments, and inquiries in relation to the world around them.

Although parents often credit their child with the capability of encoding a full thought through the use of a single-word, this may be an oversimplification of a very complex process. Due to constraints of attention, memory and knowledge, and difficulty with organizing information for storage and retrieval, it is difficult to establish the underlying meaning of the young child's single-words (ErvinTripp, 1973; Olson, 1973; Slobin, 1973). These meanings are generally restricted in comparison to that of the adult, but adequately communicate such relations as possession, existence, nonexistence, disappearance, recurrence, action, location, and attribution.

By the end of the second year of life, the child may produce 200 to 300 different words and be able to name most common everyday objects (Lipsitt, 1966; Wehrabian, 1970). These words are used to gain attention, name objects for people and to attain some object or information (Owens, 1988). The two-year-old is able to communicate some feelings, desires, interests and emotions (Owens, 1988). According to Oviatt (1982), the two-year-old begins to realize that a word refers to a related group of referents, rather than to a specific or type of referent.

The average three-year-old produces a lexicon of about 900 to 1,000 words, usually used to express present events (Lipsitt, 1966; Wehrabian, 1970). The three-year-old uses negative words, "no," 
"not," "can't," "don't," and "won't," interchangeably and uses interrogatives, "what," "where," "why," and "how," infrequently (Owens, 1988). Some noun modifiers, articles, plurals, possessive -'s, pronouns, prepositions and some -ed and -ing word endings are used (Owens, 1988).

The four-year-old produces about 1,500 to 1,600 different words (Lipsitt, 1966; Wehrabian, 1970). Here, the child begins to demonstrate categorization skills which may be influenced by increases in memory, recal1, and storage abilities (Owens, 1988). The four-year-old can count by rote to five, name primary colors, and label some coins (Owens, 1988). The child at this age is also able to use words to relate past events (Owens, 1988). Declarative, negative, interrogative and imperative forms, as well as conjunctions such as "and," "but," and "if" are being used more frequently and appropriately (Owens, 1988). Also, modifiers, articles, third person singular, present tense $-s$, auxiliary verbs and most regular and irregular past tense verbs are used more consistently when required.

By the time the child is ready to enter kindergarten (age five), they can produce an average of 2,100 to 2,200 words (Owens, 1988). It is estimated that the child has added approximately five words to his lexicon daily between the ages of $1 \frac{1}{2}$ and 6 years (Carey, 1978).

Although his definitions of words lack the completeness of adult meanings, the five-year-old's expressive vocabulary and the understanding of words and their relationships continues to grow. The child is also recognizing the need to clarify messages for the listener and be more subtle in their use of language. 
Delayed Development

At the present time, relatively little is known about the early lexical development of language delayed children. Studies of delayed children have primarily observed that these children acquire their first words later than normal children (Weeks, 1974) and that language develops at a slower rate than that observed for normal children (Johnston and Schery, 1976; Morehead and Ingram, 1973).

Leonard et al. (1982) examined the early lexical acquisition of unfamiliar words in language impaired 2:8 to 4:2 year olds and linguistically matched normal children $1: 5$ to $1: 10$ years of age. Results of this study revealed that each group of children acquired the same number of unfamiliar words. The authors suggest that the similarities between these groups may be because lexical development may not be difficult for language-impaired children when concentrated linguistic stimulation is provided.

Leonard et al. (1982) also found that object words dominated in the words learned by language-impaired children, which is similar to findings of normal children. Also, the language-impaired children were just as likely to produce words consistent with their phonologies as words with sounds outside their repertoires.

Schwartz and Leonard (1985) examined the facilitating effects of unsolicited lexical imitation on spontaneous and posttest productions of 16 unfamiliar object and action words. Subjects included 13 language-impaired children ranging from $2: 8$ to $3: 1$ years of age. Unfamiliar words were individually chosen for each child, with half of the words representing phonological characteristics within the 
child's phonology (in-phonology) and half of the words representing phonological characteristics not reportedly in the child's repertoire (out-of-phonology). The children were exposed to the experimental words 5 times each in 1045 -minute sessions.

Results indicated that the language-impaired children imitated an average of 51 percent of the experimental words. These results are similar to the 61 percent level of imitation reported for younger (1:4 to 2:0 year olds) normally developing children in a study by Leonard, Chapman, Rowan, and Weiss (1983). Also consistent with findings from normally developing children, imitating a word first did not lead to more rapid acquisition of that word (Schwartz and Leonard, 1985). The authors found that when words were imitated first, the initial spontaneous usage of those words occurred later than for words that were not first imitated. A number of words, primarily object and in-phonology words, were produced spontaneously within the first five to ten presentations and were not typically imitated before used spontaneously (Schwartz and Leonard, 1985).

A strong relationship was found between imitation and spontaneous use of a novel word. The children spontaneously used relatively few of the words that were not imitated, and they imitated very few words that were not produced spontaneously (Schwartz and Leonard, 1985). The authors also noted a significant decrease in the number of imitations following the second spontaneous use of that word. These results are also consistent with findings of normally developing children (Leonard et al., 1983). 
Posttest data indicate that the average number of words produced by the language-impaired children are comparable to the number produced by the younger children using the same task (Leonard et a1., 1983). Further, imitative use of a word increased the likelihood that the word would be produced during posttesting.

In conclusion, it appears that children with expressive language delays develop vocabularies similar to those of normal children, but at a slower rate of acquisition.

\section{RECEPTIVE VOCABULARY}

\section{Normal Deve lopment}

Although numerous studies have been devoted to the development of language production, relatively fewer have attempted to explain children's understanding of language. Two reasons that may account for this is the difficulty to assess all that young children comprehend and the degree to which comprehension is aided by contextual cues (Chapman, 1978).

Within the first few months of life, the infant can differentiate contrasting phonemes (Eimas, 1974), intonation patterns and speech from nonspeech (Nakazima, 1962). Between five and seven months, infants can distinguish between friendly and angry voices, and will follow some commands and retrieve requested objects (Owens, 1988). According to a study by Liebergott, Ferrier, Chesnick, and Menyuk (1981), infant response rates to maternal requests increased from 39.5 percent at 9 months to 52 percent at 11 months. 
The 8- to 12-month-old child understands a few single words within a routine context by looking at objects the speaker looks at, acting on objects noticed by the speaker, or imitation an ongoing action of another (Pau1, 1987).

It is fairly agreed upon that during the second year of life, the child will understand more words than are spoken (Goldin-Meadow, Seligman, Gelman, 1976; Chapman, 1982). The 12- to 18-month-old will understand single words outside of established routines but stil1 requires some contextual support for comprehension (Pau1, 1987).

The 13-month-old will have a receptive vocabulary of about 50 words, increasing rapidly to approximately 20,000 to 24,000 by age six (Paul, 1988; Owens, 1988).

It has been suggested that young children use a "fast mapping" strategy, allowing inference to occur between a word and its referent after possibly one encounter (Carey and Bartlett, 1978; Pinker, 1982; Dollaghan, 1985). According to Carey and Bartlett (1978), this may be a two-step process of lexical acquisition. The child's first encounter with a new word will constitute only a small fraction of the total information of the complete learning of the word. The second phase, dubbed "extended mapping," occurs over a period of time with several encounters with the word in which the child gradually refines the definition with new information (Carey, 1978).

Delayed Deve lopment

To date, very little is known about the way language-delayed children develop lexical comprehension. 
According to Leonard et al. (1982), the language-impaired children in their study, ranging in age from $2: 8$ to $4: 2$ years, comprehended more words than they produced and were shown to comprehend a significantly greater number of object words than action words. These results are consistent with those of normally deve1oping children at a younger age.

Dollaghan (1987) compared the fast mapping abilities of 11 language-impaired and 11 normal children ranging in age from 4:0 to 5:6 years of age, who were exposed one time to the unfamiliar object name koob $(/ \mathrm{kub} /)$ and its referent (an oddly shaped white plastic ring). The children were then tested on their ability to comprehend, produce, locate and recognize the unfamiliar word.

Results indicated that the language-impaired and normal children demonstrated several fast mapping processes. In the comprehension task, 82 percent of the children in each group correctly identified the nove 1 word. In the location task, 73 percent of the children in each group correctly identified the location of the novel object. On the production task, 64 percent of the normal children and 9 percent of the language-impaired children successfully named the novel object. Two of the normal children and three of the language-impaired children who did not attempt to name the object were given a recognition task. These children were ask to select the correct label from three nonsense syllables. These included the correct label (/kub/), a foil differing by a single phoneme (/sub/), and a foil containing no similar phonemes (/tid/). Both of the normal children recognized 
the correct label, while only two of the three language-impaired children recognized the correct label.

The author suggests that the language-impaired children's difficulty in recalling the novel word's phonological characteristics may be due to storage or retrieval deficits.

Rice, Buhr, and Nemeth (1990) also studied fast mapping abilities of language delayed five-year-olds compared to MLU- and chronologically age-matched (CA) normal children. Each group was exposed to a videotaped narrative containing unfamiliar object, action, attribute, and affective state words.

Postviewing comprehension testing revealed that the languageimpaired children demonstrated some fast mapping abilities. However, their performance over the four-word categories was significantly less than that of their MLU- or CA-matched normal comparison groups (Rice et a1., 1990). The language-impaired children comprehended 1.5 new words, compared to the gain of 2.3 new words for the MLU-matched and 4.22 new words for the CA-matched normal controls. Each group made highest gains in object and attribute words.

RELATIONSHIP BETWEEN RECEPTIVE AND EXPRESSIVE VOCABULARY

\section{Norma 1 Deve Iopment}

The relationship between the modalities of language comprehension and expression remains highly controversial. Bloom (1974) contends that comprehension and production are mutually dependent but different underlying processes. 
In contrast to Bloom's view, Ingram (1974) claims that a comprehension-production gap exists in the language development of normal children. Ingram also believes that comprehension ahead of production is a linguistic universal of acquisition.

Clark and Hecht (1984) claim that certain language elements and rules exist that are learned only through production. They further conclude that production and comprehension development follow different routes.

Most studies have found that comprehension of lexical items precedes the production of those items. Benedict (1979) found that the mean age at which her subjects comprehended 50 words preceded the age at which they produced that many words by four to six months and that comprehension developed more rapidly.

It may be oversimplified to say that production of a lexical item lags behind comprehension of that item. This implies that words comprehended first would be the first to appear later in production. According to findings by Clark and Hecht (1983) and Benedict (1979), the early receptive and productive vocabularies of a child are often quite different. Furthermore, the vocabularies of two-year-olds studied by Goldin-Meadow et al. (1976) revealed that the discrepancy between comprehension and production was greater for action names than for object names and that this discrepancy for both decreased as production increased. Goldin-Meadow et al. (1976) found that none of their 12 two-year-olds who were correct on any item on the production task failed the same item on the comprehension task. 
De layed Deve lopment

Most of what we know about the relationship between receptive and expressive vocabulary acquisition is based on studies of normal children. Relatively less is understood about this relationship for language-delayed children.

According to Leonard et a1. (1982), the language-delayed children in their study revealed comprehension-production gaps favoring comprehension, as evidenced with normal children.

\section{SUMMARY OF VOCABULARY DEVELOPMENT}

The process of receptive and expressive vocabulary development of normal and delayed children was discussed. There is evidence that children with expressive and/or receptive vocabularly delays develop vocabularies similar to that of normal children, but at a slower rate. Because the processes of language acquisition are so complex, our exact understanding of the relationship between receptive and expressive vocabulary is unclear and controversial. However, research suggests that both are equally essential to the language learning process.

\section{PEABODY PICTURE VOCABULARY TEST - REVISED}

\section{The Peabody Picture Vocabulary Test - Revised (PPVT-R) was} developed by Dunn and Dunn in 1981 as a formal measure of hearing vocabulary. It is normed for individuals aged 2 years 6 months through 40 years of age. Raw scores are converted to age equivalent values, percentile rankings, standard scores, and stanines. 
The PPVT-R was constructed to be a more sophisticated instrument than the original version, the Peabody Picture Vocabulary Test (Dunn, 1959). The subjects in the norming sample were chosen based on population data from the 1970 U.S. Census for age, sex, geographical representation, parental occupation, ethnic representation, and community size.

The PPVT-R has been subject to extensive reliability assessments. Split-half reliability coefficients of raw scores for children and youths (ages $2 \frac{1}{2}$ through 18), ranged from .67 to .88 on Form $\mathrm{L}$ (median .80 ) and from .61 to .86 on Form M (median .81). For adult standardization (ages 19 through 40), only Form L was administered. Coefficients ranged from .80 to .83 (median .82 ). Test-retest reliability coefficients for both immediate and delayed retest of alternate forms ranged from .52 to .91 .

No statistical validity is available for the PPVT-R. Content validity was based on an initial poo 1 of 3,885 words, in 19 categories, from a complete search of Webster's New Collegiate Dictionary (Merriam and Merriam, 1953). The authors assume that the PPVT-R ". - meets adequate standards for a picture vocabulary test measuring hearing vocabulary in Standard English" (p. 59).

Evidence of internal consistency (or test item) validity was determined as the stimulus words were chosen. Test items were included based on a gradual increase in the ability of the subjects to respond correctly to the item for each increasing age group. Research regarding the PPVT-R is extensive. Most of these 
studies compare the PPVT-R with other measures of reception, inteliigence, achievement, and use with special populations.

Naglieri and Naglieri (1981) compared performances on the PPVT-R and the PPVT with 88 children ranging in age from 2:6 to 5:11 years. They report scores obtained from the PPVT were significantly higher than those of the PPVT-R. These results are consistent with findings by Choong and McMahon (1983) who compared Form A and B of the PPVT with Forms $L$ and $M$ of the PPVT-R. Eighty children ranging in age from $3: 6$ to $4: 6$ were tested. Results indicated that PPVT mental ages were consistently higher than age equivalents of the PPVT-R. Mean age equivalents of the PPVT-R were found to be significantly closer to the chronological ages of those children tested.

McCallum and Bracken (1981) also compared alternate forms of the

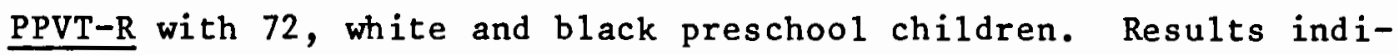
cated that differences between Form $L$ and $M$ mean standard scores were nonsignificant for whites, males and females. However, Form L appeared to be more difficult for black preschoolers than Form M.

In comparing the PPVT-R with measures of intelligence, Bracken and Prasse (1983) report a study in which the PPVT-R Forms L and M, and the McCarthy Scales of Children's Abilities were administered to 35 "at risk" preschool children ranging in age from 47 to 58 months. The children were identified "at risk" at birth because of prematurity, complications at birth, etc. The results of this study indicated correlations in the moderate range between the PPVT-R and the McCarthy Scale scores (from .41 to .69). The lowest correlation was found between the PPVT-R Form $L$ and the McCarthy Motor Scale, with 
the highest correlation occurring between Form $M$ of the PPVT-R and the General Cognitive Index (GCI) of the McCarthy Scales. It is suggested by the authors that the moderate correlations between these two measures are expected due to the different skills being tested. The authors further suggest that "The PPVT-R should not be viewed as an intelligence test, since the test is quite restricted in terms of the skills it measures" (p. 15).

Bracken and Prasse (1983) determined correlations between Forms $\mathrm{L}$ and $\mathrm{M}$ of the PPVT-R to be moderately strong (.87) which suggests that the two forms ". . can be used interchangeably with little loss of accuracy" (p. 14). These results are consistent with findings by Worthing, Phye, and Nunn (1984), who also found comparability between the two forms. However, differences between Forms $L$ and $M$ when compared to the Revised Wechsler Intelligence Scale For Children (WISC-R) were noted. Worthing et al. (1984) administered the

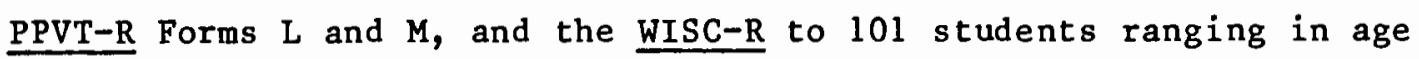
from $6: 7$ to $16: 11$. The subjects were identified as being learning disabled, mentally disabled, and emotionally disabled, When analyzing Forms $L$ and $M$ for equivalence, Form $L$ showed a stronger correlation with the WISC-R than did Form M. The authors imply that the PPVT-R is not justified in being the only measure of a child's verbal intelligence, particularly in the case of Form $M$, as it correlated lower with the WISC-R than did Form L.

Hollinger and Sarvis (1984) compared PPVT-R standard scores with the Verbal Scale, Performance Scale, and the Full Scale of the WISC-R of 53 developmentally handicapped children aged 7 to 13 years. 
Results revealed that $\underline{P P V T-R}$ scores significantly underestimated those of the WISC-R subtests. The authors suggest that the PPVT-R is an adequate measure of receptive vocabulary and language ability, but not as a measure of performance abilities or global intelligence. Bing and Bing (1985) compared the PPVT-R and the Kaufman Assessment Battery for Children ( $\underline{\mathrm{K}-\mathrm{ABC}}$ ) with a population of predominately black Head Start children. Moderate correlations were found between the two measures, with the PPVT-R tending to produce lower scores than those from the $\mathrm{K}-\mathrm{ABC}$. Interestingly, children scored an average of 15 points higher on the Expressive Vocabulary subtest of the $\mathrm{K}-\mathrm{ABC}$ than for the PPVT-R. However, the authors suggest that the

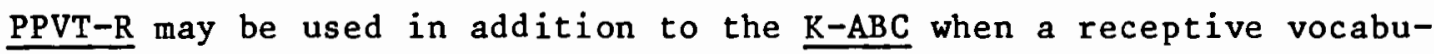
larly measure is desired.

The PPVT-R has not only been compared to cognitive and achievement measures, but also to a variety of other tests of receptive vocabulary. In a study conducted by Friend and Channe1 (1987), scores between the PPVT-R and the Picture Vocabulary ( $\underline{\mathrm{PV}}$ ) subtest of the Test of Language Development - Primary (TOLD-P) were compared. A total of 144 normal children in first, second, and third grades were administered the $\underline{P P V T}-\mathrm{R}$ and the $\underline{\mathrm{TOLD}-\mathrm{P}} \underline{\mathrm{PV}}$ subtest. It was expected by the authors that there would be a strong correlation between the two receptive vocabulary measures. However, results indicated only moderate correlations at each grade leve1, with correlations of .512 for the first grade, .580 for the second grade, and .648 for the third grade. Also noted was that the strength of correlation increased slightly as grade level increased. The authors indicate that: 
- - although a significant relationship exists between the TOLD-P PV subtest, and the PPVT-R, apparently the same information is not being tested in the two measures. The merely moderate correlations would also suggest the TOLD-P PV subtest be used as a screening rather than a diagnostic tool: It should be used in conjunction with the PPVT-R, not as a substitute ( $\mathrm{p}$. 234).

\section{EXPRESSIVE ONE-WORD PICTURE VOCABULARY TEST}

The Expressive One-Word Picture Vocabulary Test (EOWPVT) was designed by Gardner in 1979. Gardner's purpose in developing this test was to ". . obtain a basal estimate of a child's verbal intelligence by means of his or her acquired one-word expressive vocabulary" ( $p .6)$. The test is designed for children aged 2 years through 11 years 11 months. The test was developed to provide norms that would include mental ages, intelligence quotients, percentile rankings, and stanines. It is designed to be used as a screening tool for possible speech defects, learning disorders, auditory processing, auditory visual association, to evaluate bilingual student fluency in English, and to determine preschool placement.

The EOWPVT was normed on 1,607 children exclusively from the San Francisco Bay area. Subjects in the norming sample were chosen based on racial-cultural factors, sex, and age, although no breakdown of ethnic makeup or sex by age or grade level is provided.

Reliability of the EOWPVT was determined by the split-half method. Reliability coefficients ranged from .87 to .96 with a median of .94. Standard error of measurement (SEM) is also available for interpretation of scores. Although these coefficients are 
acceptable, the author makes no mention of test-retest reliability, or errors that may be attributed to examiner variance (Altepeter, 1983).

Content validity was established by the careful selection of items representing a common core of English words that could be illustrated in picture form without ambiguity. Items included were those yielding a greater percent passing with increasing age. In addition, item validity was established by correlating item scores with total test score and with the Peabody Picture Vocabulary Test (Dunn, 1959).

Criterion-related validity was determined by correlating IQ scores of the EOWPVT with other measures of intelligence, achievement and receptive vocabulary. There appears to be a higher correlation between the EOWPVT and language related (e.g., vocabulary) measures than for indicators of intelligence or aptitude and achievement.

Few studies to date have been conducted in evaluating the EOWPVT. In a study by Stoner and Spencer (1983), sex differences in the expressive vocabulary of Head Start children was investigated, using the EOWPVT. A t-test for independent data indicated no significant difference between the means $(\underline{t}=.76)$ of the deviation IQ's of the EOWPVT for the 56 males ranging in age from 45 to 76 months, and the 52 females ranging in age from 45 to 76 months. The authors report that these findings indicate no sex differences in the verbal abilities of preschool children exist.

The EOWPVT has also been used in research. Fische1, Whitehurst, Caulfield and DeBaryshe (1989) used the EOWPVT as a pre- and 
post-test measure to determine improvement in expressive language over a 5-month period with 26 expressively language-disordered twoyear-olds. Improvement after five months was variable for these children, with approximately one-third showing no improvement, onethird showing mild improvement, and one-third in the normal range at the time of post-testing.

PEABODY PICTURE VOCABULARY TEST AND THE EXPRESSIVE ONE-WORD PICTURE VOCABULARY TEST

Goldstein, Allen and Fleming (1982) report that the EOWPVT yielded mean mental ages and standard scores that were very similar to PPVT mental ages and standard scores. The subjects used were 32 children between the ages of $3: 1$ and $6: 11$, identified as being borderline or mildly retarded. Mean mental ages for the EOWPVT and the $\underline{\text { PPVT }}$ were 34.41 and 36.00 , respectively. Mean standard scores were found to be 64.13 for the EOWPVT and 65.16 for the PPVT, with a moderate correlation of $r=.63$. The authors report that the close agreement between these scores suggest that ". . on average, these measures of expressive and receptive language development yield similar results for such children (borderline and mildly retarded)" (p. 317). The authors also suggest caution in generalization of these findings, and express the need of future research on the EOWPVT with both normal and exceptional children.

In a study by Teuber and Furlong (1985), the EOWPVT and the $\underline{\text { PPVT-R }}$ were administered to 50 bilingual Mexican-American children in grades 3 through 5. The students' performance on these two tests, as 
we11 as their error patterns, were examined. The mean EOWPVT and

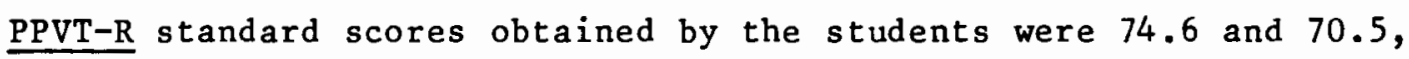
respectively. Concurrent validity coefficients were found to be in the moderate range $(r=.72)$.

Although students tended to have slightly higher standard scores on the EOWPVT than for the PPVT-R, the EOWPVT had eight difficult items as determined by low passing rates, while the PPVT-R had only two items judged as difficult. Failure rate for the EOWPVT was found to be 44.9 percent, compared to the 27.9 percent for the PPVT-R. However, higher EOWPVT error rates still resulted in higher standard scores.

The outcome of this study shows that the EOWPVT standard scores were slightly higher than the PPVT-R scores. The authors indicate that some". - items on the EOWPVT may be biased for MexicanAmerican children; that is, they have different passing rates for Mexican-American children" (p. 271).

In a study by Channe 11 and Peek (1989), the PPVT-R, EOWPVT, the Picture Vocabulary subtest of the TOLD-P, and the Receptive One-Word Picture Vocabulary Test (ROWPVT) were administered to 36 norma1 4-

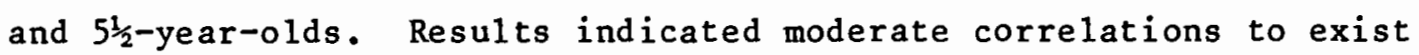
among the four tests, with the highest correlation unexpectedly found between the PPVT-R and the EOWPVT $(r=.77)$.

\section{SUMMARY OF TESTS}

The literature reviewed indicates that researchers are divided on the use of the PPVT-R. Most studies support its use 
as a formal measure of receptive vocabulary, while many negate its use as an indicator of intelligence.

At present, research concerning the EOWPVT is minimal. Most researchers express concern about its validity and reliability when used with various populations. 
CHAPTER III

METHODS AND PROCEDURES

METHODS

$\underline{\text { Subjects }}$

The subjects for this study include 45 children between 36 and 47 months currently participating in a "Late Talkers" longitudinal study at Portland State University under the direction of Rhea Paul, Ph.D. The subjects were recruited from local pediatric clinics and from local newspaper and radio advertisements. The subjects for this study were divided into three groups: expressively language delayed (ELD), normal children with a history of languge delay (HELD), and children with normal language development. The ELD group consisted of 15 children between 36 and 44 months. These children were initially considered "late talkers" at the time the children were between 24 and 34 months of age because they produced less than 50 words or no two-word combinations. These children continue to show expressive language delays at age three by exhibiting MLU's one standard deviation or more below chronological age (Miller, 1981). The $10 \mathrm{children}$ in the HELD group ranging from 36 to 43 months of age were also considered "late talkers" at 24 to 34 months, but by age 3 , they produced MLU's with 1 standard deviation of chronological age (Miller, 1981). The 20 children with a normal history of language 
development at age two and demonstrating MLU's within one standard deviation of chronological age at age three were placed in the normal group (Miller, 1981). These children range in age from 36 to 47 months. Age ranges, means, and standard deviations of age levels for each group are presented in Table I.

\section{TABLE I}

AGE RANGES, MEANS, AND STANDARD DEVIATIONS FOR THE NORMAL, ELD AND HELD GROUPS

$\begin{array}{llll}\text { Group } & \text { Range } & \text { Mean } & \text { SD } \\ \text { Norma1 } & 36-47 & 39.1 & 3.17 \\ \text { ELD } & 36-44 & 39.2 & 2.54 \\ \text { HELD } & 36-43 & 37.3 & 2.16\end{array}$

The Myers and Bean (1968) four-factor scale was used to determine socio-economic status. This scale ranges from one to five with one being the highest. Ranges, means, and standard deviations of socio-economic status and the sex distributions for each group are reported in Table II.

TABLE II

SOCIO-ECONOMIC STATUS RANGES, MEANS AND STANDARD DEVIATIONS AND SEX DISTRIBUTIONS FOR EACH GROUP

\begin{tabular}{lcccccc} 
& \multicolumn{2}{c}{ Socio-Economic Status } & & \multicolumn{2}{c}{ Sex (in Percent) } \\
\cline { 2 - 5 } Group & Range & Mean & SD & & Male & Female \\
\cline { 2 - 3 } Norma & $1-5$ & 2.25 & 1.45 & $60 \%$ & $40 \%$ \\
ELD & $2-5$ & 3.53 & 1.06 & 67 & 33 \\
HELD & $1-4$ & 2.40 & 1.07 & 90 & 10
\end{tabular}

For a complete listing of the demographic data, refer to Appendix A. 
Parents of all the subjects participating in the "Late Talkers" study signed permission forms and were asked to fill out the Language Deve lopment Survey (LDS) (Rescorla, in press) (Appendices B and C). The LDS was used to assess the children's level of expressive vocabulary.

To be eligible for the study, all subjects had to pass a hearing screening at $25 \mathrm{~dB}$ in a sound field and show normal intelligence by receiving a score of 80 or above on the Mental Development Index of The Bayley Scales of Infant Development.

\section{ASSESSMENT INSTRUMENTATION}

Peabody Picture Vocabulary Test (PPVT-R)

The PPVT-R is comprised of 175 plates each containing 4 pictures, available in two parallel forms designated $L$ and $M$. Test items are arranged in order of increasing difficulty. The subject's task is to select the picture that best illustrates the meaning of the stimulus presented orally by the examiner.

The raw score is calculated by subtracting the number of incorrect responses from the number of the ceiling item. The raw score is converted to an age equivalent, standard score equivalent, percentile ranking, and a stanine score. See Appendix D for sample test form.

\section{Expressive One-Word Picture Vocabulary Test (EOWPVT)}

The EOWPVT is comprised of 110 plates, containing one picture per plate. Test items are arranged in order of increasing 
difficulty. The subject's task is to name each picture as presented by the examiner.

The raw score is calculated by subtracting the number of incorrect items from the number of the ceiling item. The raw score is converted to a mental age, standard score, percentile ranking, and a stanine score. See Appendix E for sample test form.

\section{PROCEDURES}

\section{Intake Evaluation at Age Two}

From parent reports of expressive vocabulary size and word combinations, the children were classified as either "late talkers" or normal based on the 24 to 34 month criteria described under "Subjects" above.

\section{Follow-Up Evaluation at Age Three}

Formal language tests (including Form $M$ of the PPVT-R and the EOWPVT) were administered individually to each subject and scored according to their respective manuals. MLU was also computed for each child from audio taped samples of spontaneous speech during parent-child play interactions according to Brown's (1973) rules. Computation of MLU was determined using procedures described by Mi1ler (1981). The subjects were classified as either norma1, ELD, or HELD based on the 36 to 43 month MLU criteria described under "Subjects" above. MLU ranges, means and standard deviations for each group are presented in Table III. 
Data Analysis

MLU, PPVT-R, and EOWPVT ranges, means and standard deviations were calculated for each group. A comparison was made of PPVT-R and EOWPVT standard score means with paired t-tests using the systat computer program. MLU, PPVT-R, and EOWPVT means for total cases were further analyzed with a Pearson $r$ correlation, also using the Systat computer program.

\section{TABLE III}

MLU RANGES, MEANS, AND STANDARD DEVIATIONS FOR THE NORMAL, ELD AND HELD GROUPS

$\begin{array}{llll}\text { Group } & \text { Range } & \text { Mean } & \text { SD } \\ \text { Norma1 } & 2.88-5.4 & 4.174 & .829 \\ \text { ELD } & 1.5-2.6 & 1.968 & .308 \\ \text { HELD } & 2.53-3.84 & 3.257 & .509\end{array}$


CHAPTER IV

RESULTS AND DISCUSSION

RESULTS

The purpose of this investigation was to determine if a difference exists between mean standard scores of the $\underline{P P V T-R}$ and the EOWPVT within the three groups: normal, ELD and HELD three-year-old children.

The question posed by this study was: Is there a significant difference between group mean standard scores of the PPVT-R and the EOWPVT within groups of normal, ELD and HELD children. The ranges, means, and standard deviations of the two tests for each group are reported in Table IV.

\section{TABLE IV}

STANDARD SCORE RANGES, MEANS, AND STANDARD DEVIATIONS OF THE PPVT-R AND THE EOWPVT FOR EACH GROUP

\begin{tabular}{lrrrrrrr} 
& \multicolumn{3}{c}{ PPVT-R } & & & \multicolumn{3}{c}{ EOWPVT } \\
\cline { 2 - 8 } Group & Range & Mean & SD & & Range & Mean & $\underline{\text { SD }}$ \\
Norma1 & $90-133$ & 113.15 & 11.90 & & $80-143$ & 118.05 & 15.87 \\
ELD & $63-118$ & 92.07 & 17.54 & & $55-115$ & 84.00 & 16.78 \\
HELD & $92-119$ & 103.60 & 9.68 & & $86-124$ & 102.50 & 12.14
\end{tabular}


Standard score means for each group and total cases were compared using paired sample t-tests. These results are shown in Table V. Differences between test standard score means for each group and total cases were considered significant at the .01 level.

\section{TABLE V}

$\underline{t}$-TEST VALUES OF THE PPVT-R VS. EOWPVT STANDARD SCORE MEANS FOR EACH GROUP AND TOTAL CASES

\begin{tabular}{|c|c|c|c|c|c|}
\hline Group & Mean Diff. & SD Diff. & $t-$ & $\mathrm{df}$ & $\mathrm{p} \leq$ \\
\hline Normal & -4.900 & 13.541 & -1.618 & 19 & NS \\
\hline ELD & 8.067 & 17.665 & 1.769 & 14 & .01 \\
\hline HELD & 1.100 & 6.983 & .498 & 9 & NS \\
\hline Tota 1 & 0.756 & 14.874 & .341 & 44 & NS \\
\hline
\end{tabular}

There were no significant differences found between standard score means for the normal and HELD groups or total cases; however, a significant difference between means was found within the ELD group

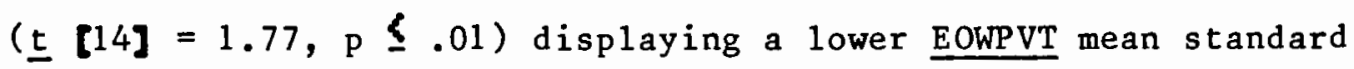
score.

Correlations using Pearson's r revealed moderate associations to exist among the two tests and MLU for total cases. The results of these correlations are presented in Table VI and were a11 considered statistically significant at the $\mathrm{p} \leq .05$ level.

The correlation between the two tests was moderate $(r=.718$, $\mathrm{p} \leq .05)$, as was the correlation of the PPVT-R with MLU ( $\mathrm{r}=.597$, $\mathrm{p} \leqq .05)$ and the EOWPVT with $\underline{\mathrm{MLU}}(\mathrm{r}=.702, \mathrm{p} \leq .05)$. 
TABLE VI

PEARSON $r$ CORRELATIONS FOR THE PPVT-R, EOWPVT, AND MLU FOR TOTAL CASES

$\underline{\text { MLU }} \quad \underline{\text { PPVT-R }} \quad \underline{\text { EOWPVT }}$

\begin{tabular}{llll}
$\frac{M L U}{\text { PPVT-R }}$ & $1.000^{*}$ & & \\
EOWPVT & $0.597^{*}$ & $1.000 *$ & $1.000 *$ \\
\hline
\end{tabular}

$\star_{p}^{*}<.05$ significance

\section{DISCUSSION}

This investigation sought to answer the following question: Is there a significant difference between group mean standard scores on the PPVT-R and the EOWPVT within groups of norma1, ELD and HELD children.

Results of the $\underline{t}$-tests show that the only significant difference between the PPVT-R and the EOWPVT test score means was in the ELD group. This difference reflects a lower EOWPVT mean standard score in a group where expressive language delay was known to exist. These findings suggest that the EOWPVT was able to successfully discriminate children previously assessed as expressively language delayed from those with normal language development.

Pearson $r$ correlations were used to determine the relationship between the two tests and their individual relationships to MLU for total cases. The PPVT-R and the EOWPVT were found to moderately correlate with each other and to MLU. The correlation between the EOWPVT and MLU was stronger than the correlation of the $\underline{\text { PPVT }-R}$ and MLU. It appears that the two tests, while measuring separate aspects of children's vocabulary development, yield similar results. The 
correlation between the PPVT-R and the EOWPVT found in this study are in agreement with those found by Teuber and Furlong (1985) $(r=.72)$ and Channe 11 and Peek (1989) $(r=.77)$.

The significant correlation between the PPVT-R and the EOWPVT to MUU, despite their differences in content (receptive/expressive vocabulary v.s. syntax through spontaneous speech), suggests that the processes of production and comprehension are related for children developing language. Dale and Henderson (1987) found a similar correlation of the PPVT-R to MLU with 85 developmentally delayed preschoolers and kindergartners $(r=.50, p<.01)$. The authors speculate that "the processes of production and comprehension may draw on the same knowledge base and processing abilities to such an extent that they may invariably be highly correlated" (p, 185).

In summary, the results of this study are consistent with previous research in the literature supporting the validity of the $\underline{\text { PPVT }-R}$ and the EOWPVT as measurements of children's receptive and expressive vocabulary. The results show that the EOWPVT was more discriminating in identifying delayed expressive vocabulary in children with expressive language delays from the normal and HELD children. The PPVT-R and the EOWPVT were found to be moderately correlated with each other and to MLU for the three-year-old children in this study. 
CHAPTER V

SUMMARY AND IMPLICATIONS

SUMMARY

The use of vocabulary tests is widely considered vital for language screening and diagnosis of lexical impairments in preschoolaged children. The assessment of both receptive and expressive vocabulary abilities is important for both clinical decision making and guided research. Unfortunately, previous research has primarily focused on the development and measurement of normal child vocabulary. Far less is known on how delayed children develop vocabulary or respond to vocabulary test measures.

The purpose of the present study was to determine if a difference exists between mean standard scores of the $\underline{P P V T}-\mathrm{R}$ and the EOWPVT. The subjects used were 45 3-year-olds participating in a longitudinal study at Portland State University. These subjects were divided into groups of normal, expressively language delayed, and normal with a history of expressive language delay. The children were grouped according to $\underline{\mathrm{MLU}}$ performance. The $\underline{\mathrm{PPVT}-\mathrm{R}}$ and EOWPVT were selected because of their similarity in linguistic domain and test construction. It was thus expected that a strong correlation between the two measures occur. 
The mean standard scores for both tests were computed for each group and total cases. Differences were determined by comparing the results within the three groups and total cases using t-tests and were considered significant at the .01 level. The only difference found was a significantly lower EOWPVT mean score relative to the PPVT-R in the ELD group.

Pearson $r$ correlations revealed moderate associations to exist between the two test means for total cases. Moderate correlations were also found between each test and $\underline{M L U}$ for total cases. Correlations were significant at the .05 level. Although all these correlations were significant, the EOWPVT was more strongly related to MLU than the PPVT-R. This suggests that EOWPVT scores are more closely associated with a general index of expressive language skill than are PPVT-R scores. In addition, the EOWPVT does distinguish children identified as ELD. Both of these findings support the validity of the EOWPVT as a measure of productive language skil1 in preschoolers.

\section{IMPLICATIONS}

Research Implications

The findings from this study appear to support the use of the $\underline{\text { PPVT-R }}$ and the EOWPVT, but the need for further research is recommended. A limitation of this study is the restricted number of subjects used, particularly the ELD and HELD groups. 
Studies with normal and delayed subjects from different age groups than from the restricted age group used in the present study would be helpful in determining possible limitations of the PPVT-R and/or the EOWPVT as vocabulary measurements with various age groups.

It is also recommended that both tests be compared with MLU with different age groups to further understand the complex relationship of receptive and expressive vocabulary to the language development of both normal and delayed children.

Another area of further research would be to compare the PPVT-R and the EOWPVT to other vocabulary and language measures with mixed age groups. This would aid in providing additional concurrent validity to both tests.

\section{Clinical Implications}

The results of this study are not offered as conclusive evidence, but it appears that the $\underline{\text { PPVT-R }}$ and the EOWPVT are helpful instruments to the speech-language pathologist in screening and diagnosing normal and delayed vocabulary in young preschool children.

It is suggested that the clincian use multiple formalized tests rather than the PPVT-R or the EOWPVT only in the diagnosis of normal or delayed language, of which vocabulary is one aspect. 
REFERENCES

Altepeter, T. (1983). A discussion of the expressive one-word picture vocabulary test. School Psychology Review, 12, 106-109.

Benedict, H. (1979). Early lexical development: Comprehension and production. Journal of Child Language, 6, 183-200.

Bing, S.B., and Bing, J.R. (1985). Comparison of the $K-A B C$ and PPVT-R with head start children. Psychology in the Schools, 22, 245-249.

Bloom, L. (1974). Talking, understanding, and thinking. In R. Schiefelbusch and Lloyd (Eds.), Language perspectives: Acquisition, retardation and intervention. Baltimore: University Park Press.

Bracken, B.A., and Prasse, D.P. (1983). Concurrent validity of PPVT-R for "at risk" preschool children. Psychology in the Schools, 20, 13-15.

Brown, R. (1973). A first language. Cambridge: Harvard University Press.

Carey, S. (1978). The child as word learner. In M. Halle, J. Bresnan, and G. Miller (Eds.), Linguistic theory and psychological reality. Cambridge: MIT Press.

Carey, S., and Bartlett, E. (1978). Acquiring a single new word. Papers and Reports on Child Language Development, 15, 17-29.

Channe11, R.W., and Peek, M.S. (1989). Four measures of vocabulary ability compared in older preschool children. Language, Speech, and Hearing Services in Schools, 20, 407-420.

Chapman, R. (1978). Comprehension strategies in children. In J. Kavanaugh and $w$. Strange (Eds.), Speech and language in the laboratory, school and clinic. Cambridge: MIT Press.

Chapman, R. (1981). Computing mean length of utterance in morphemes. In J. Miller (Ed.), Assessing language production in children. Baltimore: University Park Press. 
Chapman, K., Leonard, L.B., Rowan, L.E., and Weiss, A.L. (1983). Inappropriate word extensions in the speech of young languagedisordered children. Journal of Speech and Hearing Disorders, 48, 55-62.

Choong, J., and McMahon, J. (1983). Comparison of scores obtained on the PPVT and the PPVT-R. Journal of Speech and Hearing Disorders, $48,40-43$.

Clark, E.V., and Hecht, B.F. (1983). Comprehension and production. Annual Review of Psychology, 34, 325-347.

Clark, E.V., and Hecht, B.F. (1984). Comprehension and production in language acquisition. Annual Review of Psychology, 34, $325-350$.

Dale, P.S., and Henderson, V.L. (1987). An evaluation of the test of early language development as a measure of receptive and expressive language. Language, Speech and Hearing Services in Schools, 18, 179-187.

Dollaghan, C. (1985). Child meets word: "Fast mapping" in preschool children. Journal of Speech and Hearing Research, 28, 449-454.

Dollaghan, C. (1987). Fast mapping in normal and language-impaired children. Journal of Speech and Hearing Disorders, 52, 218-222.

Dunn, L.M. (1959). Peabody picture vocabulary test: Manual of directions and norms. Nashville: American Guidance Services.

Dunn, L.M., and Dunn, L.M. (1981). Peabody picture vocabulary test - revised. Circle Pines, MN: American Guidance Service.

Eimas, P. (1974). Linguistic processing of speech by young infants. In R. Schiefelbusch and L. Lloyd (Eds.), Language perspectives: Acquisition, retardation and intervention. Baltimore: University Park Press.

Ervin-Tripp, S. (1973). Some strategies for the first two years. In T. Moore (Ed.), Cognitive development and the acquisition of language. New York: Academic Press.

Fische1, J.E., Whitehurst, G.J., Caulfield, M.B., and DeBaryshe, B. (1989). Language growth in children with expressive language delay. Pediatrics, 82, 218-227.

Friend, T.J., and Channe11, R.W. (1987). A comparison of two measures of receptive vocabulary. Language, Speech and Hearing Services in Schools, 18, 231-237. 
Gardner, M.F. (1979). Expressive one-word picture vocabulary test manua 1. Novato, CA: Academic Therapy Publications.

Gentner, D. (1978). On relational meaning: The acquisition of verb meaning. Child Development, 49, 988-998.

Goldin-Meadow, S., Seligman, M., and Gelman, R. (1976). Language in the two-year-old. Cognition, 4, 189-202.

Goldstein, D.J., Allen, C.M., and Fleming, L.P. (1982). Relationship between the expressive one-word picture vocabulary test and measures of intelligence, receptive vocabulary, and visua $1-$ motor coordination in borderline and mildly retarded children. Psychology in the Schools, 19, 315-318.

Hollinger, C.L., and Sarvis, P.H. (1984). A comparison of the PPVT-R and WISC-R with rural children referred for assessment. Psychology in the Schools, 21, 97-102.

Huttenlocher, J. (1974). The origins of language comprehension. In R. Solo (Ed.), Theories in cognitive psychology: The Loyola symposium. New York: Wiley.

Ingram, D. (1974). The relationship between comprehension and production. In R. Schiefelbusch and L. Lloyd (Eds.), Language perspectives: Acquisition, retardation and intervention. Baltimore: University Park Press.

Ingram, D. (1976). Phonological disability in children. London: Arnold.

Johnston, J., and Schery, T. (1976). The use of grammatical morphemes by children with communication disorders. In D. Morehead and A. Morehead (Eds.), Normal and deficient child language. Baltimore: University Park Press.

Leonard, L.B., Newhoff, M., and Fey, M.E. (1980). Some instances of word usage in the absence of comprehension. Journal of Child Language, $\underline{7}, 189-196$.

Leonard, L.B., Schwartz, R.G., Chapman, K., Rowan, L.E., Prelock, P.A., Terra11, B., Weiss, A.L., and Messick, C. (1982). Early lexical acquisition in children with specific language impairment. Journal of Speech and Hearing Research, 25, 554-564.

Liebergott, J., Ferrier, L., and Menyuk, P. (1981). Prelinguistic conversation in normal and at risk infants. Paper presented to the American Speech-Language-Hearing Association convention.

Lipsitt, L. (1966). Learning processes of human newborns. Merri11-Pa1mer Quarterly, 12, 45-71. 
McCa1lum, R.S., and Bracken, B.A. (1981). Alternate form reliability of the PPVT-R for white and black preschool children. Psychology in the Schools, 18, 422-425.

Miller, J.F. (1981). Assessing language production in children: Assessing communication behavior, Volume 1. Austin: PRO-ED, Inc.

Morehead, D., and Ingram, D. (1973). The development of base syntax in normal and linguistically deviant children. Journal of Speech and Hearing Research, 16, 330-352.

Myers, J.K., and Bean, L.L. (1968). A decade later: A follow-up of social class and mental illness. New York: Wiley and Sons.

Naglieri, J.A., and Naglieri, D.A. (1981). Comparison of the PPVT and PPVT-R for preschool children: Implications for the practitioner. Psychology in the Schools, 18, 434-436.

Nakazima, S. (1962). A comparative study of the speech developments of Japanese and American children. Studies in Phonology, 2 , 27-39.

Nelson, K.E., and Bonvillian, J. (1978). Early language development: Conceptual growth and related processes between 2 and $4 \frac{1}{2}$ years of age. In K.E. Nelson (Ed.), Child's language (Vol. 1). New York: Gardner Press.

01son, G. (1973). Developmental changes in memory and the acquisition of language. In T. Moore (Ed.), Cognitive development and the acquisition of language. New York: Academic Press.

Oviatt, S.L. (1982). Inferring what words mean: Early development in infants' comprehension of common object names. Child Development, $\underline{53}, 274-277$.

Owens, R.E., Jr. (1988). Language development (2nd ed.). Ohio: Merril1 Publishing Company.

Paul, R. (1987). A model for the assessment of communication disorders in infants and toddlers. National Student Speech, Language and Hearing Association, 88-103.

Paul, R. (1988). Class notes from advanced methods of diagnosis and appraisal. Portland State University.

Pinker, S. (1982). A theory of lexical interpretive grammars. In J. Bresnam (Ed.), The mental representation of grammatical relations. Cambridge: MIT Press. 
Rescorla, L. (in press). The language development survey: A screening tool for delayed langauge in toddlers.

Rice, M.L., Buhr, J.C., and Nemeth, M. (1990). Fast mapping wordlearning abilities of language-delayed preschoolers. Journal of Speech and Hearing Disorders, 55, 33-42.

Schwartz, R.G., and Leonard, L.B. (1981). Do children pick and choose? An examination of phonological selection and avoidance in early lexical acquisition. Journal of Child Language, 9 , 319-330.

Schwartz, R.G., and Leonard, L.B. (1985). Lexical imitation and acquistion in language-impaired children. Journal of Speech and Hearing Disorders, 50, 141-149.

Slobin, D. (1973). Cognitive prerequisites for the development of grammar. In C. Ferguson and D. Slobin (Eds.), Studies of child language development. New York: Holt, Rinehart and Winston.

Stoner, S.B., and Spencer, W.B. (1983). Sex differences in expressive vocabulary of head start children. Perceptual and Motor Skills, 56, 1008 .

Teuber, J.F., and Furlong, M.J. (1985). The concurrent validity of the expressive one-word picture vocabulary test for MexicanAmerican children. Psychology in the Schools, 22, 269-273.

Weeks, T. (1974). The slow speech development of a bright child. Lexington, MA: D.C. Heath.

Wehrabian, A. (1970). Measures of vocabulary and grammatical skills for children up to age six. Developmental Psychology, 2, 439-446.

Worthing, R.J., Phye, G.D., and Nunn, G.D. (1984). Equivalence and concurrent validity of PPVT-R forms $L$ and $M$ for school-age children with special needs. Psychology in the Schools, 21, 296-299. 
APPENDIX A

DEMOGRAPHIC DATA 
DEMOGRAPHIC DATA

NORMAL GROUP

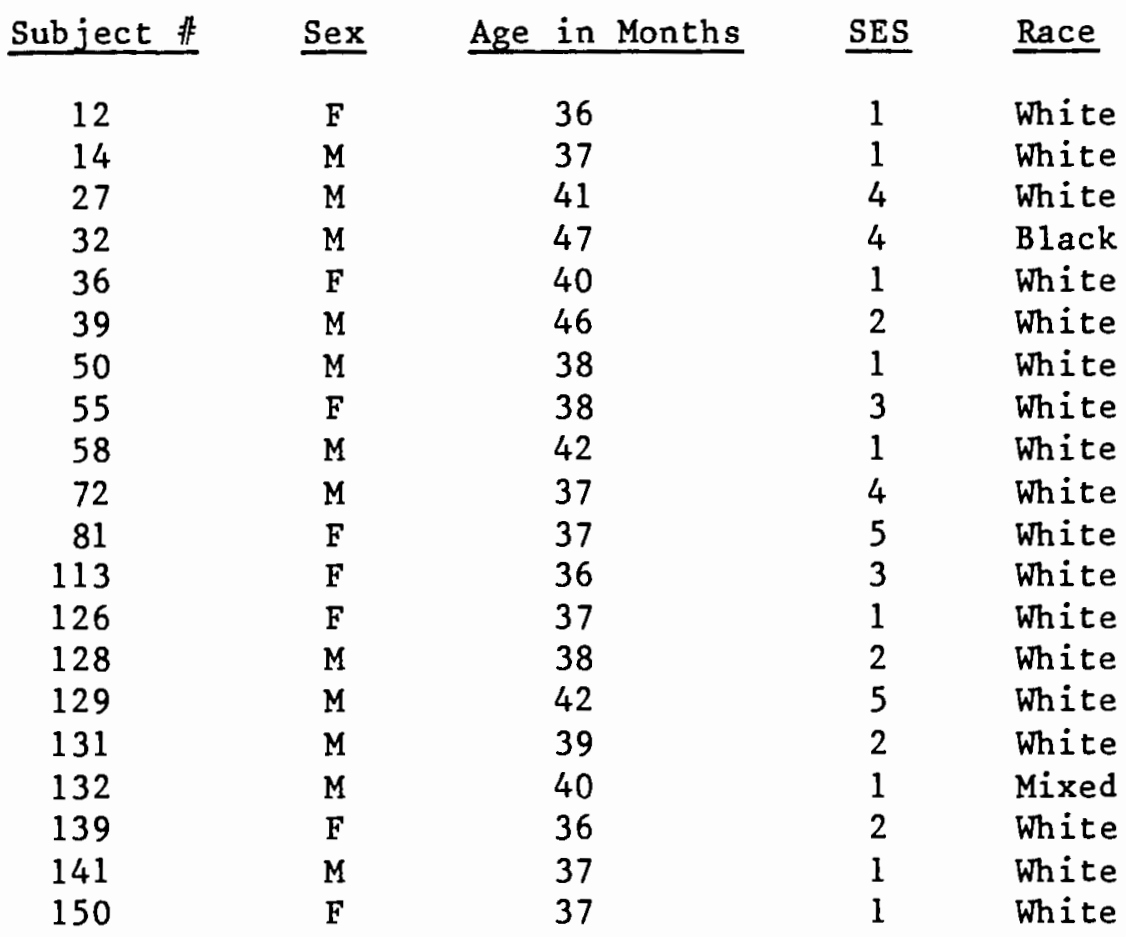


DEMOGRAPHIC DATA

\begin{tabular}{|c|c|c|c|c|c|}
\hline & & ELD & GROUP & & \\
\hline Subject 非 & $\underline{\text { Sex }}$ & Age & in Months & SES & Race \\
\hline 19 & F & & 43 & 4 & White \\
\hline 29 & F & & 39 & 5 & White \\
\hline 52 & F & & 37 & 3 & White \\
\hline 87 & F & & 37 & 3 & White \\
\hline 90 & M & & 39 & 3 & White \\
\hline 91 & M & & 39 & 3 & White \\
\hline 93 & M & & 37 & 3 & White \\
\hline 94 & M & & 40 & 3 & White \\
\hline 102 & M & & 40 & 2 & White \\
\hline 111 & F & & 40 & 5 & White \\
\hline 112 & M & & 38 & 5 & White \\
\hline 114 & M & & 36 & 2 & Mixed \\
\hline 115 & M & & 44 & 3 & White \\
\hline 116 & M & & 43 & 5 & White \\
\hline 145 & F & & 36 & 4 & White \\
\hline
\end{tabular}


DEMOGRAPHIC DATA

HELD GROUP

\begin{tabular}{|c|c|c|c|c|}
\hline Subject 非 & $\underline{\text { Sex }}$ & Age in Months & SES & Race \\
\hline 6 & M & 36 & 2 & White \\
\hline 7 & M & 36 & 2 & White \\
\hline 53 & $M$ & 38 & 4 & White \\
\hline 54 & $M$ & 43 & 3 & White \\
\hline 85 & $\mathbf{M}$ & 37 & 3 & White \\
\hline 100 & M & 36 & 1 & White \\
\hline 103 & M & 36 & 2 & White \\
\hline 105 & M & 38 & 4 & White \\
\hline 119 & M & 36 & 2 & White \\
\hline 142 & $\mathrm{~F}$ & 37 & 1 & White \\
\hline
\end{tabular}


APPENDIX B

PARENTAL CONSENT FORM 
INFORMED CONSENT

1. , hereby agree to

serve as a subject in the research project on language development in young children conducted by Rhea Paul.

I understand that the study involves seeing my child yearly for speech and language evaluation and videotaping conversations between me and my child. I understand that these tapes will be transcribed for analysis of my child's spoken language patterns.

It has been explained to me that the purpose of the study is to learn whether children who begin talking late are at risk for later learning problems.

I may not receive any direct benefit from participation in this study, but my participation may help to increase knowledge which may benefit others in the future.

Dr. Paul has offered to answer any questions I may have about the study and what is expected of me in the study. I have been assured that all information $I$ give will be kept confidential and that the identity of all subjects will rema in anonymous.

I understand that I an free to withdraw from participation in this study at any time without jeopardizing my relationship with Portland State University.

I have read and understand the foregoing information.

Date Signa ture

If you experience problems that are the result of your participation in this study, please contact the secretary of the Human Subjects Research and Review Committee, Office of Grants and Contracts, 303 Cramer Hall, Portland State University, 464-3417. 
APPENDIX C

LANGUAGE DEVELOPMENT SURVEY 
VOCABULARY CHECKLIST

Please circle each word your child says. Don't include woras your child can understand but not say. It's ok to count words that aren't pronounced clearly. If your child speaks a foreign language, please check off English versions of the words he uses.

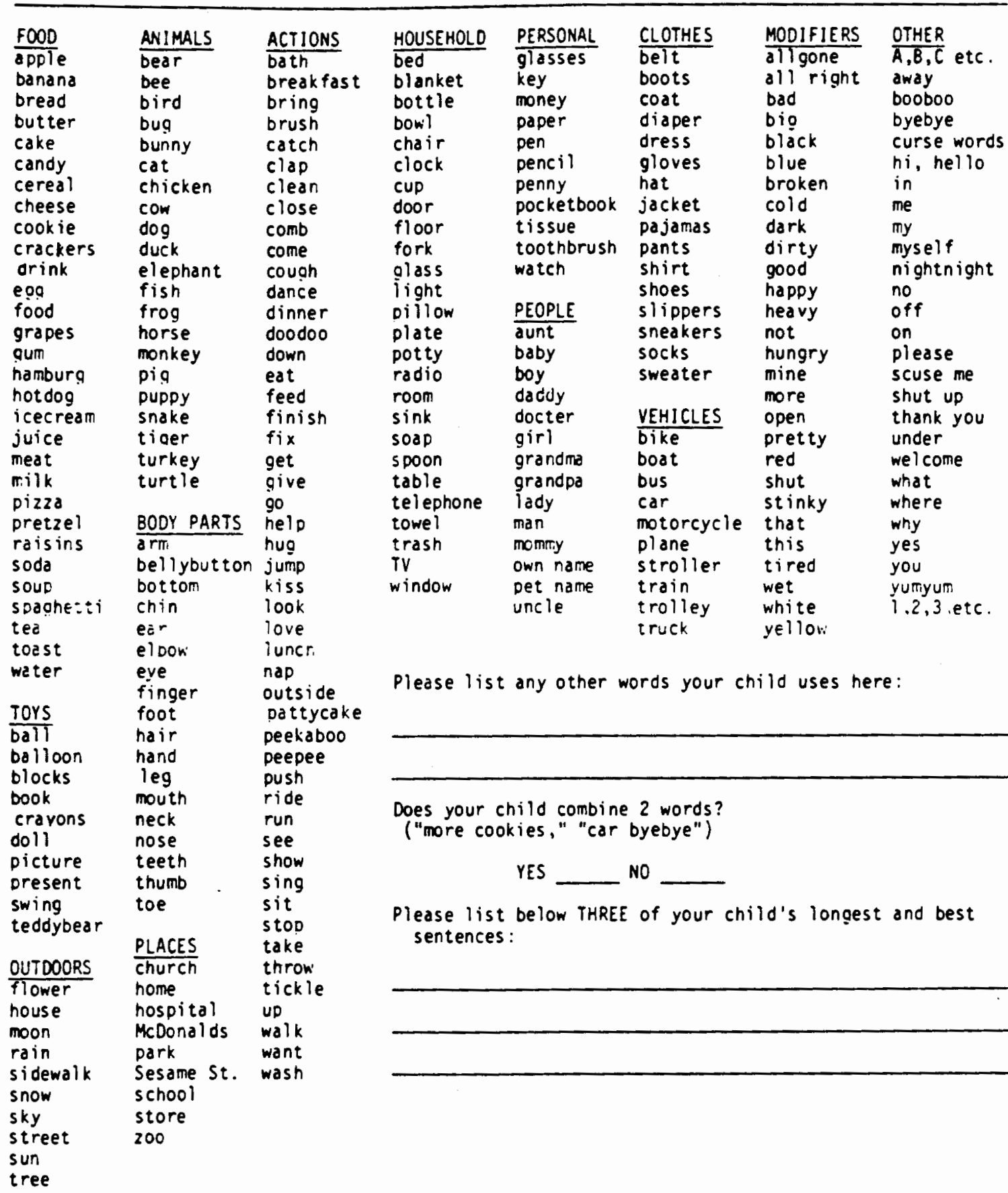


APPENDIX D

PEABODY PICTURE VOCABULARY TEST - REVISED 


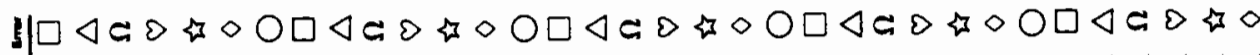
1

ป

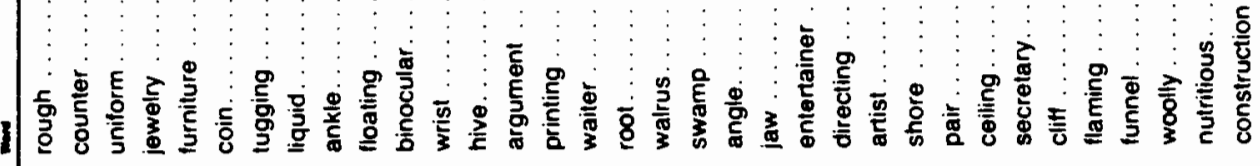

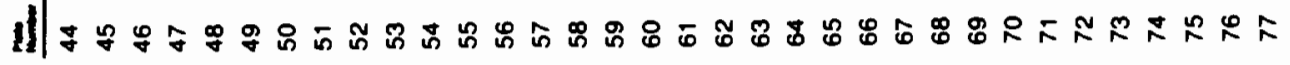

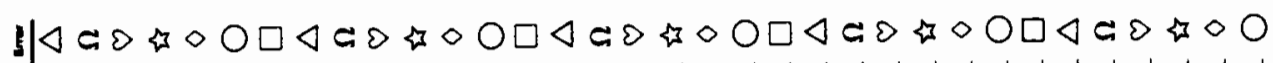

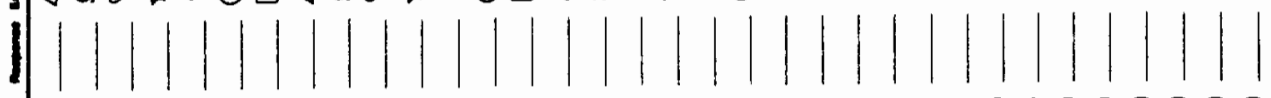

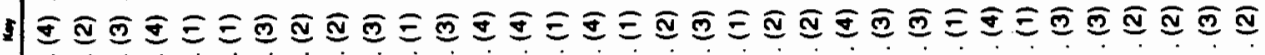

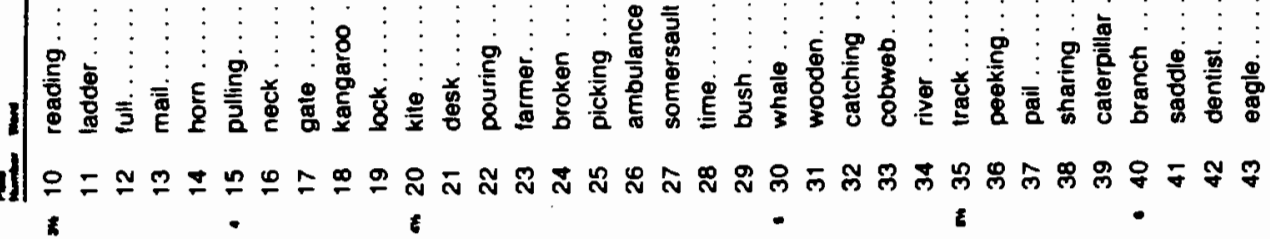

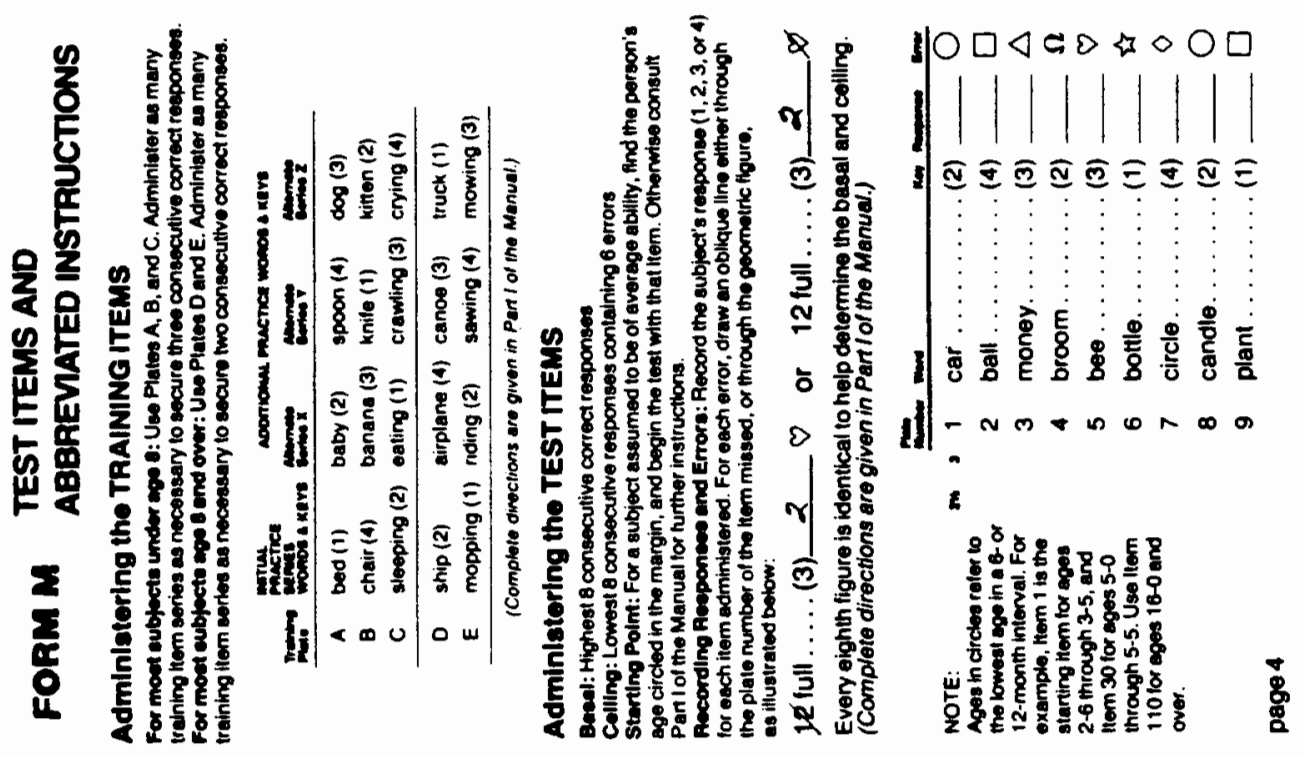




\begin{tabular}{|c|c|c|c|c|c|c|c|}
\hline & 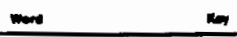 & $m$ & & & 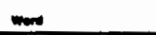 & $\mathrm{cos}$ & \\
\hline 78 & mble & & 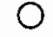 & 12 & ed & 3) & \\
\hline 79 & (4) & & $\square$ & 13 & liber & 1) & \\
\hline 80 & furious. . . . . . (1) & & $\triangle$ & 14 & portable. & (2) & \\
\hline 81 & sorting. . . . . (1) & & $\Omega$ & 15 & physician & (4) & \\
\hline 82 & musician ...... (2) & & $\vartheta$ & 16 & canine... & & \\
\hline 83 & greeting ...... (3) & & 今 & 117 & agriculture. . & (4) & \\
\hline 84 & impetition. ... (3) & & 0 & 18 & solar ..... & (2) & \\
\hline 85 & $\ldots \ldots$ (3) & & $\mathrm{O}$ & 19 & precipitation & (2) & \\
\hline 86 & antler & & $\square$ & 120 & hovering . & (3) & \\
\hline 87 & ;ting . . . . (1) & & $\triangle$ & 21 & amphibian. . & & \\
\hline 88 & $\ldots \ldots(1)$ & & $\Omega$ & 122 & dome . . & (3) & \\
\hline 89 & ng ..... (3) & & 0 & 23 & descending . & (1) & \\
\hline 90 & $\ldots \ldots(4)$ & & 它 & 124 & em & & \\
\hline 91 & assisting $\ldots \ldots$ (1) & & $\diamond$ & 125 & judicial & (2) & \\
\hline 92 & $g \ldots \ldots$ (2) & & 0 & 26 & mason. ... & (4) & \\
\hline 93 & tropical & & $\square$ & 127 & lowl..... & (3) & \\
\hline 94 & $\ldots \ldots$ (4) & & $\triangle$ & 128 & lubricating. . & (1) & \\
\hline 95 & ing . . . (4) & & $\boldsymbol{\Omega}$ & 129 & po & & \\
\hline 96 & $\ldots \ldots(2)$ & & $\theta$ & 130 & sing. . & (3) & \\
\hline 97 & ce......(1) & & 㟔 & 131 & beacon... & (4) & \\
\hline 98 & $\lg \ldots \ldots$ (3) & & 0 & 132 & attire... & (4) & \\
\hline 99 & $\ldots \ldots \ldots(3)$ & & 0 & 133 & nape .... & (2) & \\
\hline 100 & $\ldots \ldots$ (2) & & $\square$ & 134 & salutation & (2) & \\
\hline 101 & $g \ldots \ldots$ (4) & & $\triangle$ & 135 & con & (3) & \\
\hline 102 & $\ldots \ldots(3)$ & & $\Omega$ & 136 & incisor.... & (1) & \\
\hline 103 & ge ..... (1) & & $\theta$ & 137 & dwe & (1) & \\
\hline 104 & cubical & & 䒛 & 138 & orating & (1) & \\
\hline 105 & arctic. & & 0 & 139 & illumination & (4) & \\
\hline 106 & $\ldots \ldots$ (3) & & 0 & 140 & rging. & (4) & \\
\hline 107 & $t \ldots \ldots$ (3) & & $\square$ & 141 & laminated & (2) & \\
\hline 108 & banister. . . . . . (1) & & $\triangle$ & 142 & convergence & . (2) & \\
\hline 109 & composer ..... (4) & & $\Omega$ & 143 & angler. & (2) & \\
\hline O & archaeologist .. (4) & & 0 & 144 & receptacle. & (1) & \\
\hline 111 & paraliel ....... (4) & & ↔ & 145 & enticing. . & . (3) & \\
\hline
\end{tabular}

\begin{tabular}{|c|c|c|}
\hline 2 & 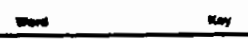 & $m$ \\
\hline 146 & stamen .......(3) & 它 \\
\hline 147 & expunging. . . . (3) & $\diamond$ \\
\hline 148 & prodigy ....... (1) & $-O$ \\
\hline 149 & encumbered ... (3) & $-\square$ \\
\hline 150 & depleted ..... (4) & $\triangle$ \\
\hline 151 & recumbent .... (1) & $\Omega$ \\
\hline 152 & equestrian. . . . (2) & 0 \\
\hline 153 & caliper. . . . . . (4) & 它 \\
\hline 154 & impale....... (1) & 0 \\
\hline 155 & ellipse $\ldots \ldots \ldots$ (4) & $\mathrm{O}$ \\
\hline 156 & apparition ..... (2) & $\square$ \\
\hline 157 & gable. . . . . . (4) & $\triangle$ \\
\hline 158 & rapiure ...... (3) & $\mathbf{\Omega}$ \\
\hline 159 & edifice....... (4) & 0 \\
\hline 160 & perusing $\ldots \ldots$ (2) & $\hat{\imath}$ \\
\hline 161 & portal ........ (1) & $\theta$ \\
\hline 162 & bovine. . . . . . (2) & 0 \\
\hline 163 & mendicant. . . . (3) & $\square$ \\
\hline 164 & arable . . . . . . (3) & $\triangle$ \\
\hline 165 & morass . . . . . (3) & $\Omega$ \\
\hline 166 & ingenious ..... (2) & $\vartheta$ \\
\hline 167 & sibling $\ldots \ldots \ldots$ (1) & $\rightarrow$ \\
\hline 168 & laciniate ......(1) & $\diamond$ \\
\hline 169 & decidwous. .... (4) & 0 \\
\hline 170 & casement .....(4) & $\square$ \\
\hline 171 & copious . . . . . (2) & $\triangle$ \\
\hline 172 & bumplious. . . . (4) & $\Omega$ \\
\hline 173 & imbibing ...... (4) & 0 \\
\hline 174 & consternation ... (3) & $\boldsymbol{\omega}$ \\
\hline 175 & Dedagogue .... (1) & 0 \\
\hline \multicolumn{3}{|c|}{$\begin{array}{l}\text { Calculating Raw Score } \\
\text { Ceiling hem } \ldots \ldots \ldots \ldots \ldots \text {. }\end{array}$} \\
\hline \multicolumn{3}{|c|}{ minus errors. } \\
\hline 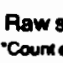 & . & \\
\hline
\end{tabular}


APPENDIX E

EXPRESSIVE ONE-WORD PICTURE VOCABULARY TEST 

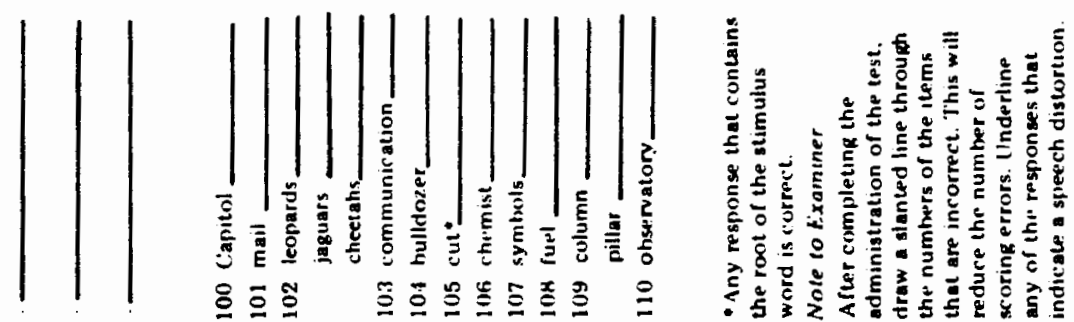

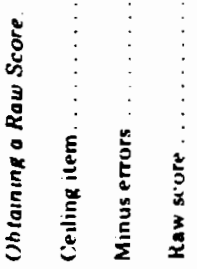
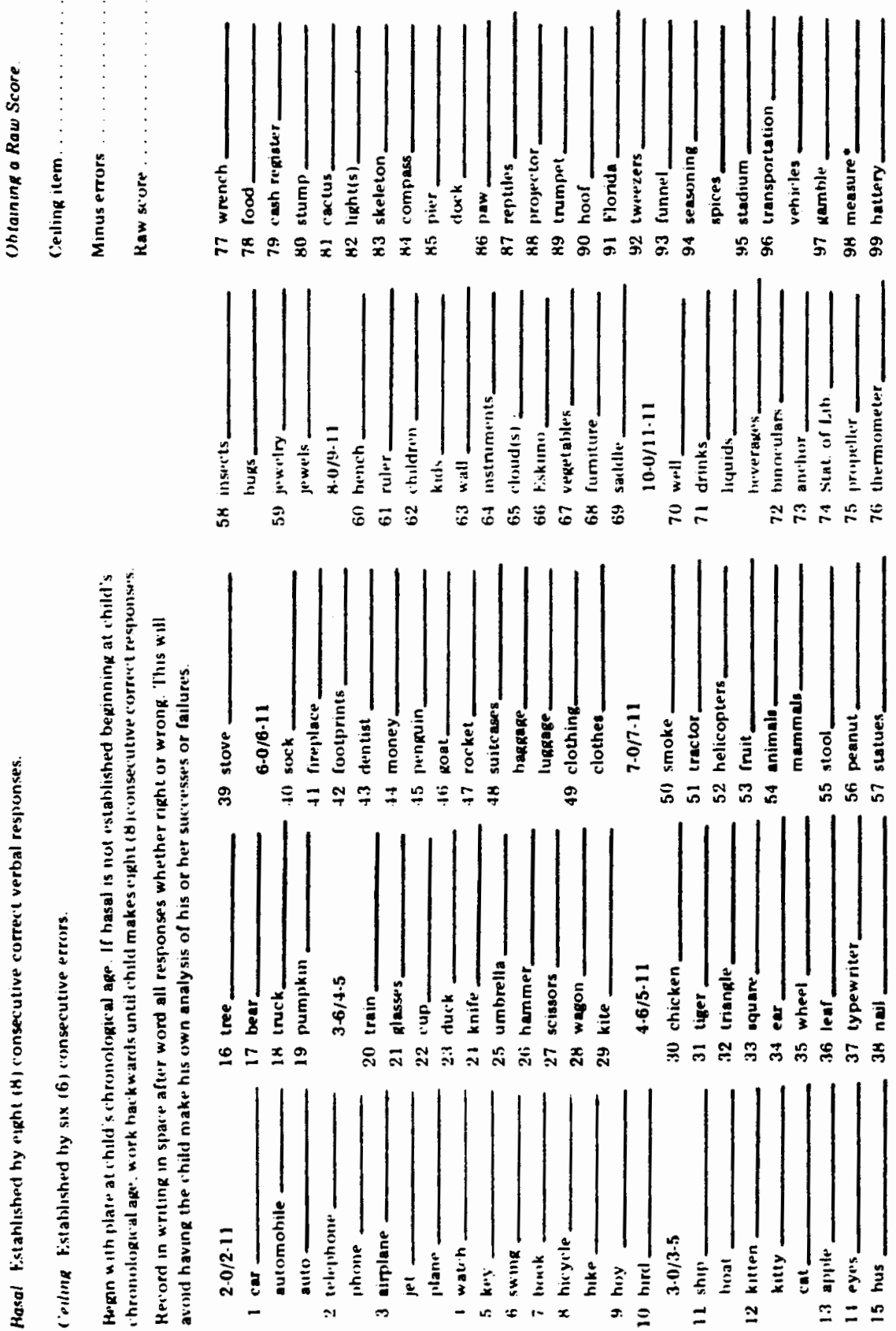